\title{
Morphology of the dentin on primary molars after the application of phosphoric acid under different conditions
}

\section{Renata Antonini Pimenta ${ }^{(a)}$ Cláudia Valéria de Sousa Resende Penido(b) \\ Roberval de Almeida Cruz(b) José Bento Alves ${ }^{(c)}$}

(a) MSc in Pedodontics; (b) PhD, Associate Professor - Department of Dentistry, Pontifical Catholic University of Minas Gerais, Belo Horizonte, MG, Brazil.

(c) PhD, Associate Professor, Department of Restorative Dentistry, Faculty of Dentistry, Federal University of Minas Gerais, Belo Horizonte, MG, Brazil.
Corresponding author: Roberval de Almeida Cruz Faculdade de Odontologia - PUC Minas Av. Dom Gaspar, 500 - Prédio 46

Belo Horizonte - MG - Brazil CEP: 30535-901

E-mail: roberval@pucminas.br

Received for publication on Mar 19, 2010 Accepted for publication on May 16, 2010

\begin{abstract}
The aim of this study was to evaluate changes in the superficial dentin pattern of primary teeth after applying different phosphoric acid concentrations and conditioning times. Twenty-four dentin surfaces were divided in 4 groups with 10 teeth each: GI - no treatment; GII to GIV - phosphoric acid at $37 \%, 32 \%$, and $10 \%$ respectively. The samples were divided into two halves: one treated for 7 seconds $\left(\mathrm{T}_{1}\right)$ and the other one for 15 seconds $\left(\mathrm{T}_{2}\right)$. They were submitted to scanning electronic microscopy (SEM). A reticule was superimposed upon the images to randomly select dentinal tubules measured in $\mu \mathrm{m}^{2}$. The conditioning times did not cause significant differences in the mean diameter values of the dentin tubules within each test group: GII $\left(\mathrm{T}_{1}=4.86 ; \mathrm{T}_{2}=4.70\right)$; GIII $\left(\mathrm{T}_{1}=3.83\right.$; $\left.\mathrm{T}_{2}=3.08\right) ; \mathrm{GIV}\left(\mathrm{T}_{1}=5.04 ; \mathrm{T}_{2}=5.23\right)$. Comparing different groups, there were no differences in $T_{1}$. The same results were observed in $T_{2}$, except for GIV which presented higher mean diameter values than GIII. The extent of acid conditioning did not influence tubule opening within groups. When different types of acids where compared, only the $10 \%$ phosphoric acid showed upper tubule opening than $32 \%$ phosphoric acid. The dentin pattern varied according to the type of acid used for conditioning.
\end{abstract}

Descriptors: Tooth, deciduous; Dentin; Acid etching, dental; Microscopy, electron.

\section{Introduction}

The effective adhesion of esthetic restorative materials to the dental surface has only been possible after the introduction of the enamel conditioning technique. Recently, treatment success has stimulated the study of procedures involving dentin, using different agents at varying concentrations and conditioning times. ${ }^{1-3}$ Most of the adhesive systems use 30 to $40 \%$ phosphoric acid conditioner to prepare the dentin surface to receive the bonding components. When dentin is etched with such phosphoric acid concentrations, the smear layer is completely removed and the surface of the dentin is morphologically changed..$^{2-4}$ Recently, single-step self-etch adhesives were introduced. ${ }^{5,6}$ One disadvantage of self-etching primer systems is the incorporation of the smear layer within the bonding interface. Although reinforced by impregnated resin, the hybridized smear layer represents a weak zone since it can result in bonding defects. ${ }^{2}$

Originally, conditioning was performed only on enamel, with acid in liquid form. Later, this was modified to the gel form in order to limit the 
conditioning area, thus avoiding dentin contamination. However, with the application of the new adhesive systems, the simultaneous conditioning of enamel and dentin has become necessary. One of the thickeners added by manufacturers to acid conditioners in gel form is silicon dioxide. It improves the gel consistency. ${ }^{4,7}$

As the tissue characteristics differ drastically, it became necessary to set the standard for adhesion to the dentin surface similar to that established for enamel. ${ }^{8}$ The adhesion process is complex. In enamel, the union is only effective in a strictly dry substrate. However, dentin displays constant moistness due to dentinal fluid. The development of adhesives that can be used in a moist environment was necessary for adhesion in dental tissue. ${ }^{9}$

The greatest barrier to the adhesion of dentin is the smear layer deposited after the use of rotating or manual instruments. ${ }^{10,11}$ It is composed of a practically non-adherent, disorganized dentin, which covers the dentin. The removal of the smear layer with phosphoric acid becomes necessary for the adhesives to interact with the dentin and thus form a hybrid layer. However, when strong acids are applied over a long period of time, in addition to the removal of residues, there is also an excessive demineralization of the peri- and intertubular dentin. This can affect the adhesion process due to a severe break in the collagen fibrils. ${ }^{12,13}$ The smear layer is easily removed from the conditioned primary teeth by using the same acid, in the same concentration and for the same length of time, as applied to permanent teeth. Thus, the use of different protocols for primary and permanent teeth becomes necessary. ${ }^{9} 14$ In this case, the conditioning time of the deciduous dentin must be approximately $50 \%$ of that recommended for permanent teeth, which is normally 15 seconds. ${ }^{15}$

Thus, the aim of this study was to analyze, both quantitatively and qualitatively, the alteration that occurs in the superficial healthy deciduous dentin after the application of phosphoric acid under different conditions.

\section{Material and Methods}

Twenty-four non-carious exfoliated human primary molars were selected for this study after the patient's informed consent was obtained under a protocol approved by the Ethical Committee of the University. The teeth were stored in deionized water and used within 3 months after exfoliation. Flat superficial dentin surfaces were created after removal of the occlusal third of the crown using a low speed diamond saw (Isomet 1000 Buehler, Lake Bluff, IL, USA) under water cooling. The surfaces were evaluated under a stereoscopic microscope (Olympus, Melville, NY, USA). The presence of any remaining enamel was removed by grinding. The smear layer was standardized by finishing the surface with 600grit silicon carbide paper (Norton, São Paulo, SP, Brazil) using the DP-U2 machine (Struers, Copenhagen, Denmark) under running water for $60 \mathrm{~s}$.

Afterwards, the longitudinal central groove in the occlusal region was plotted using a carborundum disk (Moyco Union Broach, Montgomeryville, PA, USA) to obtain two hemi-surfaces.

The four groups, with ten teeth each, are shown in Table 1. All teeth were subjected to conditioning for 7 seconds $\left(T_{1}\right)$ and 15 seconds $\left(T_{2}\right)$ at each hemisurface, respectively. Etched surfaces were washed for $20 \mathrm{~s}$ and wet-dried with air. The teeth were dried, metalized, and analyzed at $\mathrm{x} 2,000$ by SEM (Digital Scanning Microscope DSM 950, Zeiss, Germany). One hundred and forty four photomicrographs were analyzed, with 36 images for each group. Among them, 6 photomicrographs were obtained for each tooth, three from $T_{1}$ hemi-surfaces and three from $\mathrm{T}_{2}$ hemi-surfaces.

A reticule was superimposed upon the obtained images to randomly select dentinal tubules. Only the tubules at the intersection of the crosshair lines were used, according to the technique used by Mandarim-de-Lacerda ${ }^{16}$ (1995). The images were analyzed using the Confocal Assistant program (version 4.02, Build 101, University of Minnesota, USA) to avoid distortions during the overlay of images from the electronic microscope and from the crosshair technique. Dentinal tube opening was then measured using image analysis software (UTHSCSA Image Tool 2.03, University of Texas Health Science Center, San Antonio, TX, USA).

For this procedure a special cursor was used. It circled the entire area of these tubules to measure 


\begin{tabular}{|c|c|c|c|c|c|}
\hline \multirow[t]{8}{*}{$\begin{array}{l}\text { Table } 1 \text { - Group } \\
\text { descriptions. }\end{array}$} & Group & Treatment & $\begin{array}{l}\text { Conditioning } \\
\text { Time }\end{array}$ & $\begin{array}{l}\text { Phosphoric acid } \\
\text { concentration }\end{array}$ & $\begin{array}{c}\text { Trademark / Manufacturer / } \\
\text { city / country }\end{array}$ \\
\hline & GI & - & - & No conditioning & - \\
\hline & \multirow{2}{*}{ G॥ } & $\mathrm{T}_{1}$ & 7 seconds & \multirow{2}{*}{$37 \%$} & \multirow{2}{*}{$\begin{array}{l}\text { Condicionador dental gel, } \\
\text { Dentsply, Petrópolis, RJ, Brazil }\end{array}$} \\
\hline & & $\mathrm{T}_{2}$ & 15 seconds & & \\
\hline & \multirow{2}{*}{ G III } & $\mathrm{T}_{1}$ & 7 seconds & \multirow{2}{*}{$32 \%$} & \multirow{2}{*}{$\begin{array}{c}\text { Unietch, Bisco, Schaumburg, } \\
\text { IL, USA }\end{array}$} \\
\hline & & $\mathrm{T}_{2}$ & 15 seconds & & \\
\hline & \multirow{2}{*}{ GIV } & $\mathrm{T}_{1}$ & 7 seconds & \multirow{2}{*}{$\begin{array}{c}10 \% \\
\text { orthophosphoric acid }\end{array}$} & \multirow{2}{*}{$\begin{array}{l}\text { Acigel, SS White, Rio de } \\
\text { Janeiro, RJ, Brazil }\end{array}$} \\
\hline & & $\mathrm{T}_{2}$ & 15 seconds & & \\
\hline
\end{tabular}

its area. Obliterated tubules were not used in the quantitative analysis. In order to facilitate the measurement of the tubules, the images were double amplified. The measurements were recorded in $\mu \mathrm{m}^{2}$ for each area and then for each group. The recording and analysis of all images was done in a blind test and it was carried out by only one researcher.

Data were obtained from a sketch with subdivided parts, with a factorial of 2 (Time of 7 seconds X Time of 15 seconds) by 3 (37\% Acid X 32\% Acid X $10 \%$ Acid). For statistical quantification of the tube areas, Analysis of Variance (ANOVA) was performed $(\mathrm{p}<0.05)$. Qualitative aspects of the inter- and peritubular dentin were also assessed, taking into consideration the presence or absence of the smear layer.

\section{Results}

The Factorial Analysis of Variance (ANOVA) is showed in Table 2.

No difference among conditioning times within the same group could be observed: diameters of the dentinal tubules did not vary in accordance with $T_{1}$ or $\mathrm{T}_{2}$ treatment in GII, GIII, or GIV (Table 2 - columns). There was no relation between longer treatment time and greater tube diameter.

Upon comparing the different acid concentrations used at $\mathrm{T}_{1}$, no statistical difference in the tubules area could be observed among GII, GIII, or GIV. Upon comparing these same concentrations at $\mathrm{T}_{2}$, no statistical difference in average area was observed between GII and GIII or between GII and GIV. There was a difference between GIII and GIV (Table 2 - lines). Thus, with the exception of GIII treatment compared to GIV at $T_{2}$, the treatments
Table 2 - Average areas of the dentinal tubules $\left(\mu \mathrm{m}^{2}\right)$ for each experimental group in relation to conditioning time.

\begin{tabular}{c|c|c|c}
\hline & GII & GIII & GIV \\
\hline$T_{1}$ & $4.86^{\mathrm{aA}}$ & $3.83^{\mathrm{aA}}$ & $5.04^{\mathrm{aA}}$ \\
\hline $\mathrm{T}_{2}$ & $4.70^{\mathrm{abA}}$ & $3.08^{\mathrm{bA}}$ & $5.23^{\mathrm{aA}}$ \\
\hline
\end{tabular}

Different lower case letters on the same line indicate statistically different values $(p<0.05)$. Different capital letters in the same column indicate statistically different values $(p<0.05)$.

were statistically equivalent.

The changes caused by the diverse treatments carried out on the dentinal surface are shown in Figures 1 through 7. Representative photomicrographs of each group are presented. In GI (control) the dentinal surface was totally covered by the smear layer, preventing the identification of peri- and intertubular dentin as well as the opening of the dentinal tubules (Figure 1). The morphological results were similar for the different times within the same experimental group. Among different groups (GII, Figures 2-3 and GIV, Figures 6-7), the deposit of a granular layer was detected, suggesting that silicon remained. In GIV, it could be observed a greater proportion of tubules obliterated. GIII (Figures 4-5) presented a more homogeneous surface.

\section{Discussion}

The extent of acid conditioning optimal for dentinal structures has been the theme of many studies. ${ }^{12,13,15}$ Exposing the dentin of the primary teeth to acid for 15 seconds, as compared to 7 seconds, results in a thicker demineralized area. ${ }^{12,13}$ Longer conditioning times may thus lead to adhesive system penetration failures in the inner extremities of the tissue. 


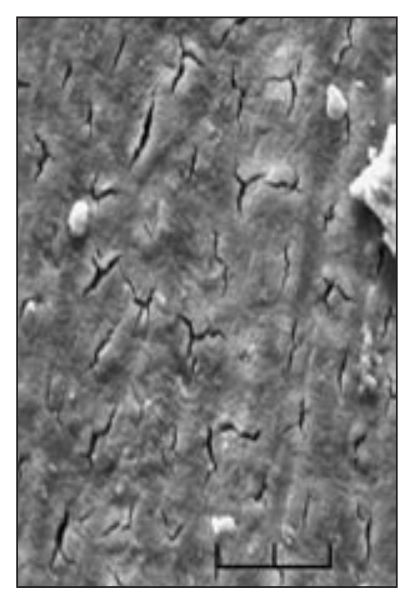

Figure 1 - Gl (control) amorphous layer - smear layer.

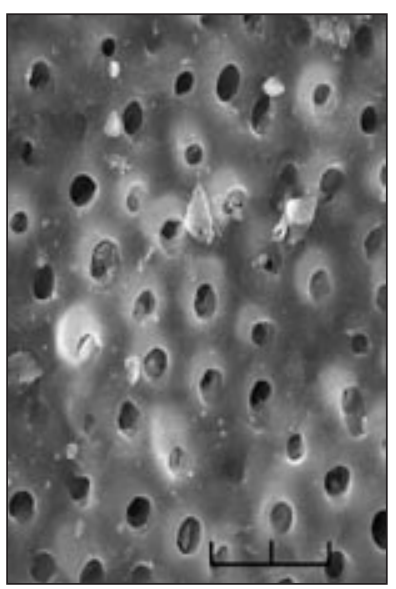

Figure 5 - Surface of dentin etched for 15 seconds with $32 \%$ phosphoric acid.

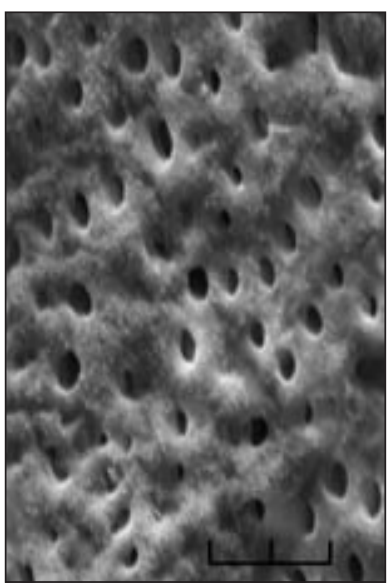

Figure 2 - Surface of dentin etched for 7 seconds with $37 \%$ phosphoric acid.

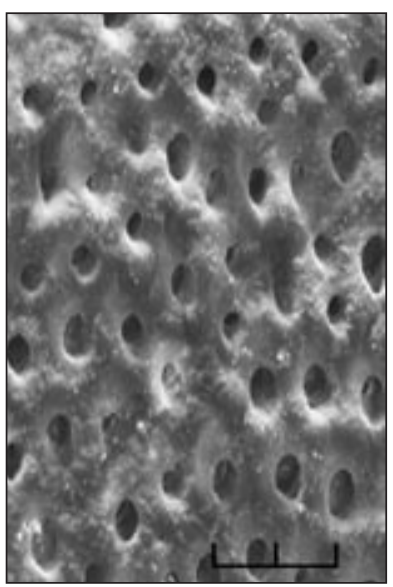

Figure 6 - Surface of dentin etched for 7 seconds with 10\% phosphoric acid.

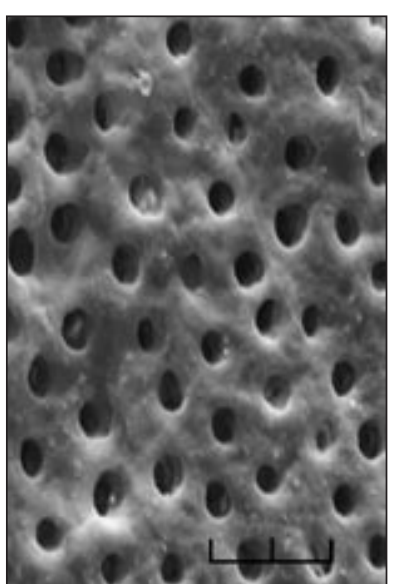

Figure 3 - Surface of dentin etched for 15 seconds with $37 \%$ phosphoric acid.

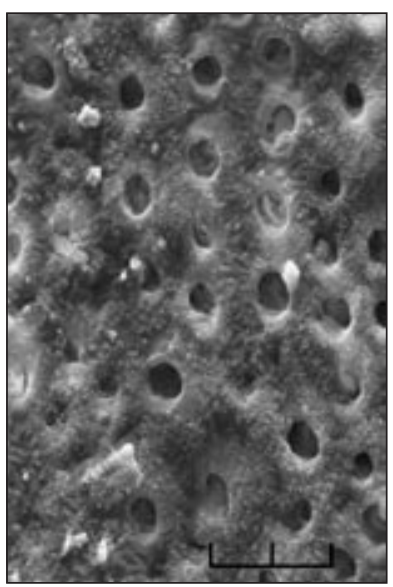

Figure 7 - Surface of dentin etched for 15 seconds with 10\% phosphoric acid.

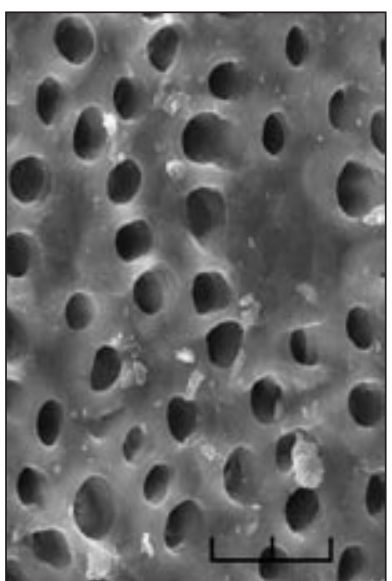

Figure 4 - Surface of dentin etched for 7 seconds with $32 \%$ phosphoric acid.
The total-etch technique attempts to remove the smear layer completely via acid etching and rinsing. The surface of the dentin is morphologically changed due to the dissolution of hydroxyapatite crystals, which leads to a wide opening of the dentinal tubules and the exposure of a layer of mineraldepleted collagen fibrils. ${ }^{2,11,17,18}$ In Figure 1, it can be observed that the smear layer was not removed, as expected for a surface that had not been submitted to acid treatment.

The concentration definition is the amount of a substance dissolved in a specified amount of solvent. In this study three different phosphoric acid concen- trations were used $(10 \%, 32 \%$ and $37 \%)$. Comparing the groups, there were no differences in $\mathrm{T}_{1}$. The same results were observed in $\mathrm{T}_{2}$, unless for GIV $(10 \%)$ which presented higher mean diameter values than GIII (32\%). This was an unexpected result.

Upon morphological analysis of the deciduous dentin after conditioning with 37\% (GII), 32\% (GIII), and $10 \%$ (GIV) phosphoric acid, it was verified the presence of the smear layer. In GIII (Figures 4-5), as compared to the other experimental groups, the smear layer were more homogeneous.

It was also observed the presence of a granular layer in GII and GIV (Figures 2, 3, 6, and 7). It was 
desirable that elemental analyses of the conditioners and the dentin surfaces were done in order to analyze this granular layer that was detected. Some authors consider that this is a direct consequence of using silicon-containing materials. ${ }^{7,19}$ Many products contain silicon to improve consistency in gel form; the presence of silicon on the dentinal surface does not interfere with dentinal adhesion. ${ }^{1,7}$ In the present study, the conditioning agents containing silicon, as compared to the conditioners without thickeners or polymer, did not completely demineralize the dentinal structure. Therefore, similar concentrations of phosphoric acid that contained different thickeners yielded varying levels of demineralization and distinct morphologies in the conditioned dentin. ${ }^{19}$

The UTHSCSA Image Tool program was used to measure the tubular area because of the software package's facility of use, precision of results, greater viewing capacity, and speed in the calculation of measurements. Crosshair overlay was considered the most efficient method for randomly selecting tubules for assessment. ${ }^{13}$

There was no difference in tube diameter and therefore in the quantity of intertubular dentin among the different treatment times. For the 7-second treatment, there were no significant differences within groups. In the 15 -second treatment group, there was a statistically significant difference in dentinal tube area between GIV and GIII. It is important to note that smaller dentinal tube openings are correlated with a greater quantity of intertubular dentin. As compared to resinous tags, intertubular dentin contributes in a greater proportion to the adhesion of the restorative material to the dentin. Additionally, acid concentration as well as conditioning time interferes in the depth of the demineralized dentin of primary teeth, which can in turn influence adhesion. ${ }^{2}$ In contrast, the acid concentration did

\section{References}

1. Perdigão J, May KN, Wilder AD, Lopes M. The effect of depth of dentin demineralization on bond strengths and morphology of the hybrid layer. Oper Dent. 2000 May-Jun;25(3):18694. not affect the resistance of adhesive materials in permanent teeth. ${ }^{4}$

A recent study investigated the influence of etching time on the degradation of resin-dentin bonds produced in primary teeth. ${ }^{14}$ After 24 hours there was no significant difference between bond strengths produced by the adhesive systems, irrespective of the acid etching time. Water storage for 6 and 12 months significantly reduced bond strengths, especially when the dentin was acid etched for $15 \mathrm{sec}-$ onds. Before recommending the use of a brief treatment period or a lower concentration of phosphoric acid at children's clinics, it is necessary to better evaluate the material adhesion resistance. Reducing the acid conditioning time of primary teeth to half that applied to permanent teeth may affect the force of adhesion. ${ }^{2,3}$ The conditioning must be effective without compromising adhesion and causing damage to the pulp tissue..$^{12,15,17}$ Since the resinous materials are applied in two structures, it is also necessary to verify whether conditioning time can also be reduced in the enamel. When dealing with very young patients, it may be advantageous to reduce the acid conditioning time without compromising the final restoration. Thus, more laboratory research and longitudinal clinical studies are needed to corroborate the proposal of a new adhesive protocol in Pediatric Dentistry.

\section{Conclusion}

The acid conditioning time of the dentin of primary teeth did not influence dentinal tube diameter within the same group. There was no difference correlated with conditioning time, with the exception of GIV, which presented a greater average tube diameter as compared to GIII after 15-second treatment. The morphology of the dentin varied according to the type of acid used for conditioning.
2. Sardella TN, Castro FL, Sanabe ME, Hebling J. Shortening of primary dentin etching time and its implication on bond strength. J Dent. 2005 May;33(5):355-62.

3. Bolaños-Carmona V, González-López S, Briones-Luján T, De Haro-Muñoz C, Macorra JC. Effects of etching time of 
primary dentin on interface morphology and microtensile bond strength. Dent Mater. 2006 Dec;22(12):1121-9.

4. Nunes MF, Swift EJ, Perdigão J. Effects of demineralization depth on microtensile bond strength to human dentin. J Adhes Dent. 2001 Summer;3(2):137-43.

5. Leite FRM, Capote TSO, Zuanon ACC. Application of the total etching technique or self-etching primers on primary teeth after air abrasion. Braz Oral Res. 2005 Jul-Set;19(3):198202.

6. Carvalho APMC, Turbino ML. Can previous acid etching increase the bond strength of a self-etching primer adhesive to enamel? Braz Oral Res. 2009 Abr-Jun;23(2):169-74.

7. Perdigão J, Denehy G, Swift Jr EJ. Silica contamination of etched dentin and enamel surfaces: a scanning electron microscopic and bond strength study. Quintessence Int. 1994 May;25(5):327-33.

8. Perdigão J, Frankenberger R, Rosa BT, Breschi L. New trends in dentin/enamel adhesion. Am J Dent. 2000 Nov;13(Spec No):25D-30D.

9. Torres CP, Chinelatti MA, Gomes-Silva JM, Borsatto MC, Palma-Dibb RG. Tensile bond strength to primary dentin after different etching times. J Dent Child (Chic). 2007 MayAug;74(2):113-7.

10. Rontani RM, Ducatti CH, Garcia-Godoy F, De Goes MF. Effect of etching agent on dentinal adhesive interface in primary teeth. J Clin Pediatr Dent. 2000 Spring;24(3):205-9.
11. Ayad MF. Effects of rotary instrumentation and different etchants on removal of smear layer on human dentin. J Prosthet Dent. 2001 Jan;85(1):67-72.

12. Nör JE, Feigal RJ, Dennison JB, Edwards CA. Dentin bonding: SEM comparison of the resin-dentin interface in primary and permanent teeth. J Dent Res. 1996 Jun;75(6):1396-403.

13. Olmez A, Oztas N, Basak F, Erdal S. Comparison of the resindentin interface in primary and permanent teeth. J Clin Pediatr Dent. 1998 Summer;22(4):293-8.

14. Sanabe ME, Kantovitz KR, Costa CA, Hebling J. Effect of acid etching time on the degradation of resin-dentin bonds in primary teeth. Am J Dent. 2009 Feb;22(1):37-42

15. Nör JE, Feigal RJ, Dennison JB, Edwards CA. Dentin bonding: SEM comparison of the dentin surface in primary and permanent teeth. Pediatr Dent. 1997 May-Jun;19(4):246-52.

16. Mandarim-de-Lacerda CA. Métodos Quantitativos em Morfologia. Rio de Janeiro: EDUERJ; 1995. 131p.

17. Perdigão J. Dentin bonding as a function of dentin structure. Dent Clin North Am. 2002 Apr;46(2):277-301.

18. Nakabayashi N, Ashizawa M, Nakamura M. Identification of a resin-dentin hybrid layer in vital human dentin created in vivo: durable bonding to vital dentin. Quintessence Int. 1982 Feb;23(2):135-41.

19. Perdigão J, Lambrecherts P, Van Meerbeek B, Tome AR, Vanhele G, Lopes AB. Morphological field emission-SEM study of the effect of six phosphoric acid etching agents on human dentin. Dent Mater. 1996 Jul;12(4):262-71. 